American Journal of Pharmacology and Toxicology 1 (3): 54-59, 2006

ISSN $1557-4962$

(C) 2007 Science Publications

\title{
CPI-1189 Protects Against Dextran Sulfate Sodium-induced Colitis in Mice
}

\author{
${ }^{1,2}$ Beverley Greenwood-Van Meerveld and ${ }^{2}$ Karl R. Tyler \\ ${ }^{1}$ Veterans Affairs Medical Center and the Oklahoma Center for Neuroscience \\ ${ }^{2}$ Oklahoma University Health Sciences Center, Oklahoma City, OK
}

\begin{abstract}
Nitrone-related therapeutics (NRTs) represent a new class of small molecules potentially effective in the treatment of inflammatory bowel disease (IBD) by protecting cells from damage caused by excess inflammation and/or oxidative stress. The goal of this study was to determine the efficacy and potency of CPI-1189, a novel therapeutic agent, in dextran sulfate sodium (DSS)-induced colitis in mice. Mice received oral doses of either CPI-1189 $\left(3,10\right.$, or $\left.30 \mathrm{mg} \mathrm{kg}^{-1}\right)$ or the methyl cellulose vehicle along with 3\% dextran sulfate in their drinking water. Assessment of colitis was by calculation of a disease activity index (DAI) and by histological observations. Signs of colitis in vehicle-treated mice were evident by day 3 using the DAI and with histological confirmation on day 7 . In mice given CPI-1189, there was a significant and dose-dependent improvement in all signs of colitis with an overall protection of approximately $50 \%$. These observations suggest that CPI-1189 is a novel, orally active, therapeutic agent that could be developed for the treatment of crohn's disease and ulcerative colitis in humans.
\end{abstract}

Key words: Colon, inflammation, nitrone-related therapeutics

\section{INTRODUCTION}

Inflammatory bowel disease (IBD) is a blanket term for the chronic, inflammatory condition experienced by individuals with either Crohn's disease or ulcerative colitis. The etiology and pathophysiology of IBD remains unknown, although several factors such as genetic, infectious and immunologic susceptibility have been implicated ${ }^{[1,2]}$. Advances in the treatment of IBD are difficult to achieve because of the lack of a full understanding of the cause of IBD. As a result, the current treatment options for patients with either Crohn's disease or colitis are limited ${ }^{[3,4]}$. The poor sideeffect profile of corticosteroids restricts their use to treating acute and serious episodes of disease, while products based on 5-aminosalicylic acid (5-ASA) as the active agent show frequent drug intolerance, limited efficacy and can only be used in mild to moderate cases. The next treatment options, if corticosteroids and 5-ASA agents fail, are powerful immunosuppressive agents such as cyclosporine, 6-mecaptopurine or azathioprine. Treatment with monoclonal antibodies to TNF- $\alpha$ is a recently introduced, novel therapeutic approach to the treatment of patients with $\operatorname{IBD}^{[5-7]}$. However, antibodies like those to TNF- $\alpha$ are not active following oral administration and the potential longterm toxic effects of these potentially immunogenic proteins remain to be determined. The lack of a safe and effective
A.

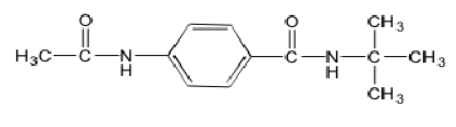

CPI-1189

B.

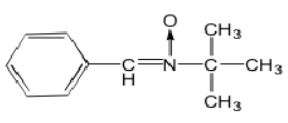

PBN

Fig. 1: Chemical structures: Structures for CPI-1189 and PBN ( $\alpha$-phenyl butyl nitrone)

pharmacological agent to treat IBD often leads to surgery, in severe cases, to remove the affected region of the small or large bowel ${ }^{[8]}$.

CPI-1189 (Fig. 1) is representative of a new class of therapeutic agent structurally related to $\alpha$-phenyl butyl nitrone, a molecule shown to mitigate oxidative stress in animal models of ischemia/reperfusion ${ }^{[9,10]}$. The mechanism of action of these compounds appears to involve protection against the damaging effects of oxidative stress including that induced by proinflammatory cytokines ${ }^{[11,12]}$ and cytokines are thought to play a critical role in the development of IBD ${ }^{[13-16]}$. In the present study we employed the dextran sulfate sodium (DSS) model of colitis which has been used extensively in mice ${ }^{[17-20]}$. The goal of the study was to investigate of the efficacy and potency of a new agent CPI-1189 in the DSS model.
Corresponding Author:

Beverley Greenwood-Van Meerveld, Ph.D., FACG, Oklahoma Center for Neuroscience, Oklahoma University Health Sciences Center, VA Medical Center, Research Administration Rm. 151, 921 N.E. 13th St., Oklahoma City, OK 73104, Tel: (405) 270-0501 ext. 3547, Fax: (405) 290-1719 


\section{MATERIALS AND METHODS}

Animals: Experiments used male mice maintained on LAB Diet certified rodent chow and tap water $a d$ libitum. The facility housing the animals controlled both illumination (12 hour light-dark cycle) and temperature $\left(21-23^{\circ} \mathrm{C}\right)$. The colitis study used male Swiss Webster mice, 30-40 g from Charles River Laboratories, Wilmington, MA. The animals, individually housed, acclimated in the animal facility for one week prior to experimentation. The Animal Use and Care Committee at the Oklahoma City V.A. Medical Center approved all animal use. The dose proportionality study used 96 days day old, male C57BL/6J mice from Jackson Laboratories, Bar Harbor, Maine. The animals acclimated in the animal facility at Centaur in Sunnyvale, CA for at least 7 days prior to experimentation. The mean body weights \pm SD of the mice in the dose proportionality study were 28.9 $\pm 2.0 \mathrm{~g}, 29.1 \pm 2.3 \mathrm{~g}, 29.2 \pm 2.2 \mathrm{~g}$ and $29.1 \pm 2.0 \mathrm{~g}$ for the $10,30,100$ and $500 \mathrm{mg} \mathrm{kg}{ }^{-1}$ dose groups $(\mathrm{n}=$ $3 /$ dose group), respectively. The animals, housed five mice per cage until the day prior to dosing and singly housed thereafter, fasted for $2 \mathrm{hr}$. prior to dosing and received food and water ad libitum $0.5 \mathrm{hr}$. after the treatment. The Animal Use and Care Committee at Centaur Pharmaceuticals, Inc. approved all animal use for the dose proportionality study.

\section{Colitis studies}

Induction of colitis in mice: To induce acute colitis, mice in the study consumed for 7 days drinking water fortified 3\% (w/v) with 45,000 average molecular weight DSS from Spectrum Chemicals.

Treatment protocol: The initial efficacy study used 16 mice divided into 2 experimental groups - one group of 10 mice dosed daily with $30 \mathrm{mg} \mathrm{kg}^{-1}$ of CPI-1189 and a second group of 6 mice dosed with the vehicle control group. On days $0-6$, each group of mice received, by oral gavage, a single oral dose of either CPI-1189 or the methyl cellulose vehicle. On days 1-7 all animals received 3\%(w/v) DSS, made fresh daily, in their drinking water one hour after the oral dosing. On the seventh day, all animals received isoflurane anesthesia (2-4\%) before euthanasia by decapitation.

The dose response study used 42 mice divided into 5 experimental groups - 3 groups (10 mice/group) each dosed daily with 3,10 or $30 \mathrm{mg} \mathrm{kg}^{-1}$ CPI-1189, a vehicle control group $(\mathrm{n}=8)$ and one naive group $(\mathrm{n}=$ 4). On days 0-6, each group of mice, except those in the naive group, received by oral gavage a single oral dose of CPI-1189 or the methyl cellulose vehicle. On days 17 all animals, except naive animals, received 3\% (w/v) DSS, made fresh daily, in their drinking water one hour after the oral dosing. On the seventh day, all animals received isoflurane anesthesia before euthanasia by decapitation. In addition, $5 \mathrm{~cm}$ segments of colonic tissue from three randomly selected mice from each group were placed in $10 \%$ buffered formalin for later histological analysis.

Evaluation of colonic damage and inflammation Disease activity index: The disease activity index (DAI) is known to be a valid measure for the acute colitis produced by DSS ${ }^{[19,20]}$. The index takes into account weight loss, stool consistency and occult bleeding on scales of 0-4 (Table 1). For each mouse, a daily DAI score was calculated as the aggregate of the $\%$ weight loss score, stool consistency score and fecal occult score divided by three. The DAI values for the groups were then reported as mean \pm se for each day of the experiment. Subsequently, the daily DAI score for each experimental group was calculated as the mean \pm se of the individual DAI scores of each mouse in the group (Table 1). Non-blinded researchers performed the scoring prior to each daily oral dose of either CPI1189 or vehicle.

Table 1: Disease activity index parameters

\begin{tabular}{lll}
\hline Parameter & Change & Score \\
\hline Weight Loss & 0 & 0 \\
& 1 to $<5 \%$ & 1 \\
& 5 to $<10 \%$ & 2 \\
Stool Consistency & 10 to $<20 \%$ & 3 \\
& $>20 \%$ & 4 \\
& Negative & 0 \\
Fecal Occult Blood & Loose & 2 \\
& Diarrhea & 4 \\
& Normal & 0 \\
& Positive & 2 \\
& Gross Bleeding & 4 \\
\hline
\end{tabular}

Histological analysis: Isolated proximal, medial and distal portions of the $5 \mathrm{~cm}$ segment of colon were placed in an embedding frame and preserved in 10\% formalin. Subsequently, the colon was sliced, mounted, stained with hemotoxylin \& eosin and then scored by a blinded pathologist who rated the tissues based on the grade of the disease, $0-4$, the percentage of the disease, $0-4$ and the severity of the inflammation, 0-3 (Table 2A-C).

Table 2A: Grade of histological disease

\begin{tabular}{ll}
\hline Grade of Disease & Score \\
\hline Crypt intact & 0 \\
Loss 1/3 crypt & 1 \\
Loss of 2/3 crypt & 2 \\
Loss of entire crypt with intact & 3 \\
surface epithelium & \\
Loss of entire crypt with erosion of & 4 \\
surface epithelium & \\
\hline Table 2B: Extent of histological damage & \\
\hline Extent of Damage (\% involvement) & Score \\
\hline $1-25 \%$ & 0 \\
$26-50 \%$ & 1 \\
$51-75 \%$ & 2 \\
$76-100 \%$ & 3 \\
\hline
\end{tabular}

Table 2C: Severity of histological damage

\begin{tabular}{ll}
\hline Score for Severity & Score \\
\hline Normal & 0 \\
Focal inflammatory cell infiltrate & 1 \\
Inflammatory cell infiltrate, gland drop out & 2 \\
and crypt abscess & 3 \\
Mucosal ulceration & \\
\hline
\end{tabular}

Drugs and chemicals: Centaur Pharmaceuticals, Inc, (Sunnyvale, CA) provided the CPI-1189 (4acetylamino-N-tert-butylbenzamide). Sigma Chemical Company, St. Louis, MO, provided the methyl cellulose used to make the dosing solution. Distilled/deionized water obtained from a MilliQ water 
system (Millipore, France). Suspensions of CPI-1189 for dosing were prepared in distilled/deionized water containing $10 \mathrm{mg}$ of methyl cellulose per ml. DSS was purchased from Spectrum Chemical, Gardena, CA and was added at $3 \%(\mathrm{w} / \mathrm{v})$ to distilled/deionized water. Occult bleeding was determined using individual hemoccult tests purchased from SmithKline Diagnostics, San Jose, CA. Isoflourane (IsoFlo, Abbott Laboratories) was purchased from J. A. Webster, Sterling, MA. Saline $(0.9 \%$ w/v $)$ was made by adding the appropriate amount of $\mathrm{NaCl}$ (Sigma Chemical Company) to distilled/deionized water. Formalin purchased from Sigma Chemical Company was diluted to $10 \%(\mathrm{v} / \mathrm{v})$ with distilled/deionized water prior to use.

\section{Expression of results and statistical analysis}

Efficacy in DSS-treated mice: Values were expressed as mean \pm se and statistically evaluated using SAS Student's t test or ANOVA as appropriate. Statistical significance was set at the $\mathrm{p}<0.05$ level and designated with an asterisk in the figures and tables given in the results section. Simple comparisons were performed using PROC NPAR1.WAY. Dose-response relationships were performed using PROC RANK followed by analysis of the normalized values using PROC GLM. If the PROC GLM results suggested a significant difference, group comparisons were performed with a Tukey post-hoc test.

\section{RESULTS AND DISCUSSION}

In all methyl cellulose vehicle-treated mice, administration of 3\% DSS in their drinking water for 7 days produced clinical signs of colitis including weight loss, diarrhea and bloody stools that were evident as early as day 3 of the treatment and were sustained throughout the study. The development of colitis was

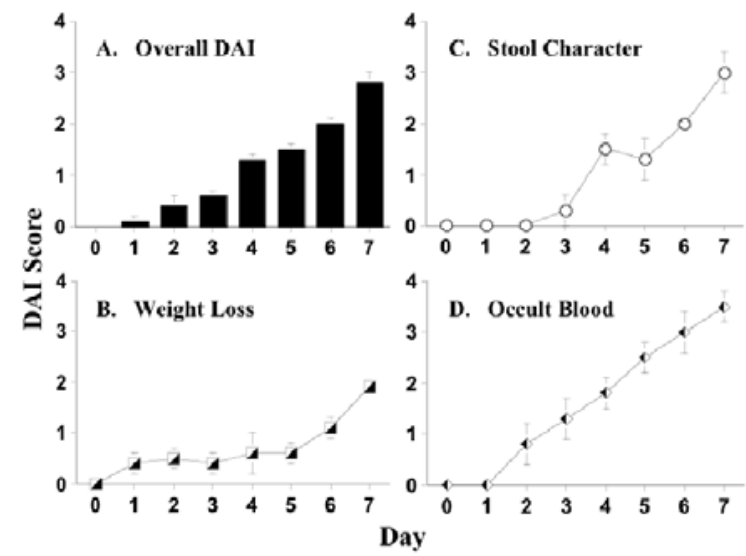

Fig. 2: Effect of DSS treatment: Disease Activity Index (DAI) score with break-down of individual parameters for mice administered 3\% DSS. A: Total score by day. B: Weight loss parameter by day. C: Stool consistency parameter by day. D: Fecal occult blood parameter by day. A steady increase in all markers of colitis occurred over the 7 day period
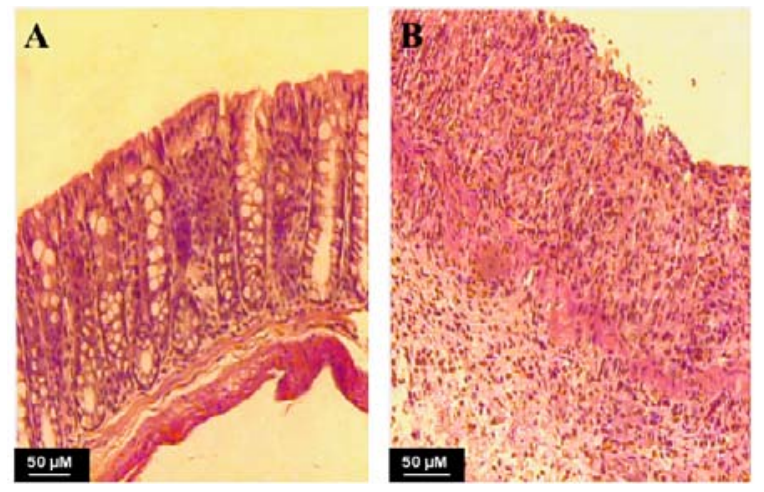

Fig. 3: Hematoxylin and Eosin (H \& E) stained section of colon from, A: Naïve control mouse and B: DSS vehicle-treated mouse. In the DSS vehicle-treated mouse, DSS ingestion resulted in marked crypt erosion and an increase in inflammatory infiltrate compared to the naïve control group

reflected in an increase in the daily DAI score (Fig. 2) and characterized histologically by crypt loss, ulcerations and a diffuse infiltration of inflammatory cells was observed in colons removed on day 7 in DSStreated mice dosed orally with methyl cellulose (Fig. 3).

Protective effect of CPI-1189 in the DSS model of colitis: In an initial series of experiments, CPI-1189 (30 $\mathrm{mg} \mathrm{kg}^{-1}$ ) was given by oral gavage once a day to mice receiving DSS in their drinking water. This dose, which in a previous study was found to completely protect in the mouse MPTP model of Parkinson's disease (unpublished observations), induced a significant protection in the DAI (Fig. 4). The protective effect of

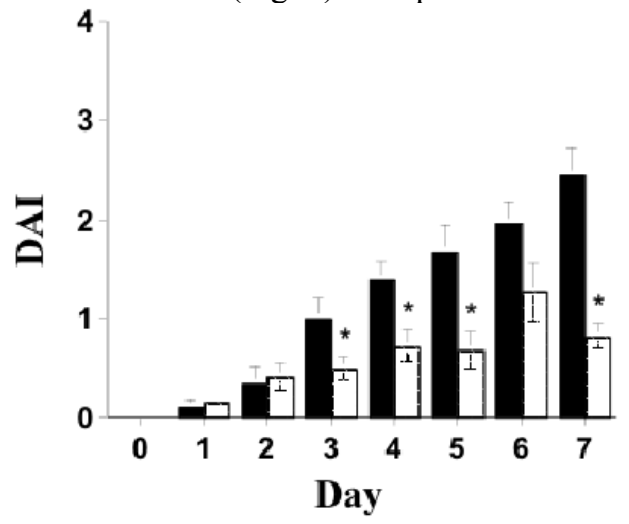

Fig. 4: Effect of CPI-1189 treatment on DAI scores in DSS-treated mice. Filled bars indicate mice that received the vehicle control. Open bars indicate mice that received $30 \mathrm{mg} \mathrm{kg}^{-1} \mathrm{CPI}-$ 1189 p.o., once-a-day. CPI-1189 treatment affords protection on most days after day 2 of DSS treatment. * denotes $\mathrm{p}<0.05$ compared to vehicle control 

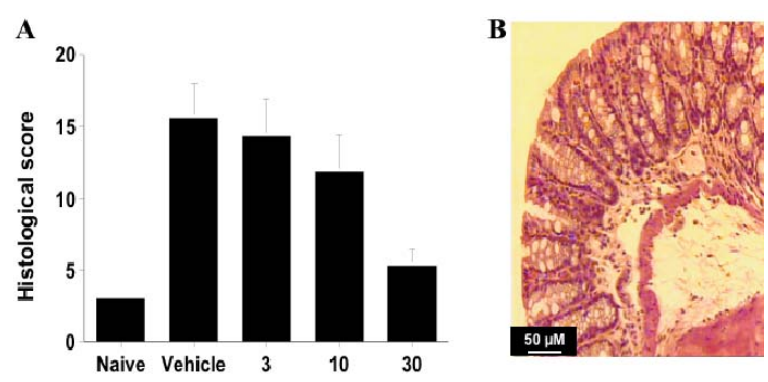

Fig. 5: Histological dose response. A: Histology scores for colonic tissue from mice in each dose group. B: Mice dosed with $30 \mathrm{mg} \mathrm{kg}^{-1}$ CPI-1189 retain almost normal histology

CPI-1189 ( $\mathrm{n}=7-10$ mice) against the DSS-induced colitis was significantly different from the vehicle treated animals $(\mathrm{n}=6$ mice) on days 3-7. The maximum protective effect by CPI-1189, greater than $50 \%$, occurred on day 7 . The histological appearance of the colons from DSS-treated mice dosed orally with CPI-1189 closely resembled colons from controls mice that were not treated with DSS (Fig. 5).

Evaluation of the dose-dependent protection of CPI1189 in the DSS model of colitis: The objective of the next experiment was to explore the dose-response characteristics of CPI-1189 in the DSS murine model of colitis. CPI-1189 $\left(3,10\right.$ or $\left.30 \mathrm{mg} \mathrm{kg}^{-1}\right)$ was given by oral gavage once a day ( $\mathrm{n}=8-10 /$ group). In this study CPI-1189 induced a significant and dose-dependent improvement in the DAI (Fig. 6). The $30 \mathrm{mg} \mathrm{kg}^{-1}$ po daily dose of CPI-1189 produced the greatest protective effect as measured by the improvement in the DAI and histological damage score. Modest, but often not statistically significant, protection was observed at a

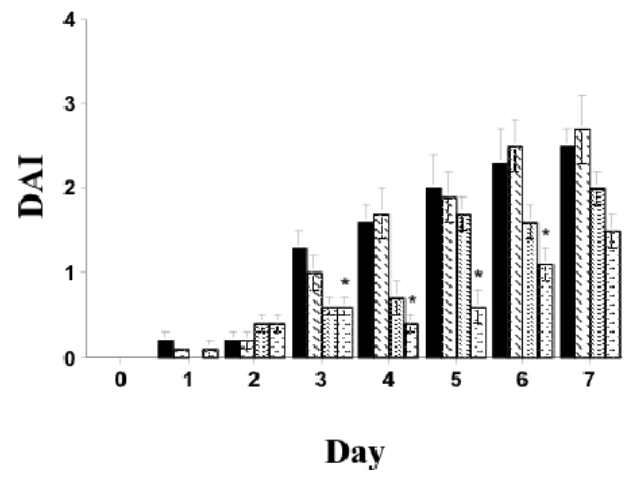

Fig. 6: DAI dose-response for CPI-1189. All mice received 3\% DSS in their drinking water starting on day 1 . Solid bars indicated vehicle control mice. Dashed bars indicated mice that received $3 \mathrm{mg} \mathrm{kg}^{-1}$ CPI-1189 p.o. Spotted bars indicate mice that received $10 \mathrm{mg} \mathrm{kg}^{-1}$ CPI1189 p.o and hatched bars indicate mice that received $30 \mathrm{mg} \mathrm{kg}^{-1} \mathrm{CPI}-1189$ p.o. There is an unmistakable dose-induced protection provided by CPI-1189. * denotes $\mathrm{p}<0.05$ compared to vehicle control

daily dose of $10 \mathrm{mg} \mathrm{kg}^{-1}$ and no protection was observed at a daily dose of $3 \mathrm{mg} \mathrm{kg}^{-1}$.

The goal of this research was to explore the activity of a novel therapeutic agent, CPI-1189, in a mouse model of colonic inflammation that reproduces some of the colonic damage observed in patients with IBD. CPI-1189, administered orally to mice given DSS in their drinking water, was found to protect mice from the DSS-induced colitis. The protective effect of CPI1189 occurred after once-a-day dosing and was dosedependent with a maximum efficacy of greater than $50 \%$ protection at $30 \mathrm{mg} / \mathrm{kg} /$ day. The protection at 30 $\mathrm{mg} / \mathrm{kg} /$ day was evident in DAI scores, in each efficacy element of the DAI index (weight, occult blood and stool consistency) and by histological examination.

The mechanism by which CPI-1189 protects in the DSS model is still not fully understood. In previous studies, CPI-1189 was found able to scavenge hydroxyl radicals to the same extent that PBN scavenges hydroxyl radicals. Thus, CPI-1189 might work as a radical scavenger to directly protect sensitive targets in cells from damage caused by reactive oxygen species. However, CPI-1189 is not a particularly effective scavenger and the available evidence is that hydroxyl radicals are not produced to any appreciable extent following treatment with $\operatorname{DSS}^{[21]}$. More likely, a potent protection by CPI-1189 against the deleterious effects of cytokines such as TNF- $\alpha$ is responsible for the activity of this agent in the DSS model. Previous research has shown that CPI-1189 protects in in vitro test systems against TNF- $\alpha$ induced apoptosis ${ }^{[22,23]}$, dihydrodichloroflourescin sensitive reactive oxygen species production ${ }^{[22]}$ and suppression of bcl-2, an endogenous anti-oxidant and anti-apoptotic agent ${ }^{[22,23]}$. In vivo, CPI-1189 protects against TNF- $\alpha$ induced apoptosis, memory loss and weight $\operatorname{loss}^{[24]}$. Interestingly CPI-1189 does not interfere with binding of TNF- $\alpha$ to either its $\mathrm{p} 55$ or p75 binding sites (unpublished observations). CPI-1189 appears to act in the signal transduction pathway activated by binding of TNF- $\alpha$ to its p55-binding site. In this regard, CPI-1189 is known to mitigate activation of a key mitogenactivated protein kinase, p38, by pro-inflammatory cytokines $^{[25]}$ and altered mitogen-activated kinases signals have been implicated in IBD [26]. The antiTNF properties of CPI-1189 are particularly important in the context of IBD because TNF- $\alpha$ is elevated in the intestines of both humans suffering from $\operatorname{IBD}^{[15,27]}$ and mice with DSS-induced colitis ${ }^{[28]}$. Moreover, the antiTNF properties of CPI-1189 are of clinical interest because of the recent finding that a monoclonal antibody to TNF- $\alpha$ (Remicade) shows activity in treating patients with refractory Crohn's disease ${ }^{[5,6]}$. 
In summary, we demonstrated that the addition of DSS (3-10\%) to the drinking water causes symptoms of colitis such as diarrhea, rectal bleeding and weight loss in mice within a few days of initiating treatment. In mice given CPI-1189 by oral gavage, there was a significant and dose-dependent improvement in DSSinduced colitis as seen by a decrease in DSS-induced diarrhea, rectal bleeding and weight loss. Moreover, there was a significant histological decrease in the DSS-induced mucosal damage. In conclusion, in an experimental model of colitis in mice, CPI-1189 is effective in protecting the colonic mucosa from damage caused by DSS. The data provides compelling support for the possible efficacy of CPI-1189 in the treatment of IBD, including ulcerative colitis and Crohn's disease.

\section{ACKNOWLEDGMENT}

This study was supported by a grant from Centaur Pharmaceuticals, Inc.

\section{REFERENCES}

1. Sartor, R.B., 1995. Current concepts of the etiology and pathogenesis of ulcerative colitis and Crohn's disease. Gastroenterol. Clin. North Am., 24: 475-507.

2. Papadakis, K.A. and S.R. Targan, 1999. Current theories on the causes of inflammatory Bowel disease. Gastroenterol. Clin. North Am., 28: 283296.

3. Robinson, M., 1998. Medical therapy of inflammatory Bowel disease for the 21st century. Eur. J. Surg. Suppl., 582: 90-98.

4. Hanauer, S.B., 1996. Inflammatory Bowel disease. N. Engl. J. Med., 334: 841-848.

5. Present, D.H., P. Rutgeerts, S.R. Targan, S.B. Hanauer, L. Mayer, R.A. van Hogezand, D.K. Podolsky, B.E. Sands, T. Braakman, K.L. DeWoody, T.F. Schaible and S.J. van Deventer, 1999. Infliximab for the treatment of fistulas in patients with Crohn's disease. N. Engl. J. Med., 340: 1398-1405.

6. Targan, S.R., S.B. Hanauer, S.J. van Deventer, L. Mayer, D.H. Present, T. Braakman, K.L. DeWoody, T.F. Schaible and P.J. Rutgeerts, 1997. A short-term study of chimeric monoclonal antibody ca2 to tumor necrosis factor alpha for Crohn's disease. N. Engl. J. Med., 337: 1029-1035.

7. Lapidus, A., O. Bernell, G. Hellers and R. Lofberg, 1998. Clinical course of colorectal Crohn's disease: A 35-year follow-up study of 507 patients. Gastroenterology, 114: 1151-1160.
8. Oliver, C.N., P.E. Starke-Reed, E.R. Stadtman, G.J. Liu, J.M. Carney and R.A. Floyd, 1990. Oxidative damage to brain proteins, loss of glutamine synthetase activity and production of free radicals during ischemia/reperfusion-induced injury to gerbil brain. Proc. Natl. Acad. Sci. USA., 87: 5144-5147.

9. Zhao, Q., K. Pahlmark, M.L. Smith and B.K. Siesjo, 1994. Delayed treatment with the spin trap alpha-phenyl-n-tert-butyl nitrone (PBN) reduces infarct size following transient middle cerebral artery occlusion in rats. Acta Physiol. Scand., 152: 349-350.

10. Floyd, R.A., K. Hensley, F. Jaffery, L. Maidt, K. Robinson, Q. Pye and C. Stewart, 1999. Increased oxidative stress brought on by pro-inflammatory cytokines in neurodegenerative processes and the protective role of nitrone-based free radical traps. Life Sci., 65: 1893-1899.

11. Conner, E.M. and M.B. Grisham, 1996. Inflammation, free radicals and antioxidants. Nutrition, 12: 274-277.

12. Harris, M.L., H.J. Schiller, P.M. Reilly, M. Donowitz, M.B. Grisham and G.B. Bulkley, 1992. Free radicals and other reactive oxygen metabolites in inflammatory Bowel disease: Cause, consequence, or epiphenomenon? Pharmacol. Ther., 53: 375-408.

13. Murthy, S., M. Gupta and N. Murthy, 1998. Implication of Reactive Oxygen Metabolites in Inflammatory Bowel Disease. In: Oxygen Radicals and the Disease Process (Eds C.E. Thomas and B. Kalyanaraman) pp: 101-126. Harwood Academic Press, The Netherlands.

14. Rogler, G. and T. Andus, 1998. Cytokines in inflammatory Bowel disease. World J. Surg., 22: 382-389.

15. Ishiguro, Y., 1999. Mucosal proinflammatory cytokine production correlates with endoscopic activity of ulcerative colitis. J. Gastroenterol., 34: 66-74.

16. Sands, B.E., 1999. Novel therapies for inflammatory Bowel disease. Gastroenterol. Clin. North Am., 28: 323-351.

17. Elson, C.O., R.B. Sartor, G.S. Tennyson and R.H. Riddell, 1995. Experimental models of inflammatory Bowel disease. Gastroenterology, 109: 1344-1367.

18. Elson, C.O., 1998. Experimental Models of Intestinal Inflammation: New Insights into Mechanisms of Mucosal Homeostatis: In: Mucosal Immunology (eds P.Ogra, J. Mestecky, W. Strober, J. Bienenstock and J.R. McGhee) pp: 1007-1024, Academic Press, New York.

19. Okayasu, I., S. Hatakeyama, M. Yamada, T. Ohkusa, Y. Inagaki and R. Nakaya, 1990. A novel method in the induction of reliable experimental acute and chronic ulcerative colitis in mice. Gastroenterology, 98: 694-702. 
20. Cooper, H.S., S.N. Murthy, R.S. and D.J. Sedergran, 1993. Clinicopathologic study of dextran sulfate sodium experimental murine colitis. Lab Invest., 69: 238-249.

21. Blackburn, A.C., W.F. Doe and G.D. Buffinton, 1998. Salicylate hydroxylation as an indicator of hydroxyl radical generation in dextran sulfateinduced colitis. Free Radic. Biol. Med., 25: 305313.

22. Pulliam, L., W.D. Flitter, W.A. Garland, R. Chun and I. Irwin, 1998. Synthetic antioxidant inhibits neurotoxins associated with AIDS dementia. Society for Neuroscience Abstracts, 24 (Part 2): 1959.

23. Irwin, I., E. MacGowan, W.D. Flitter and W.A. Garland, 1998. CPI-1189 attenuates the toxic effects of TNFalpha in SK-N-MC cells. Society for Neuroscience Abstracts, 24 (Part 2): 1959.

24. Bjugstad, K.B., W.D. Flitter, W.A. Garland, G.C. Su G and G.W. Arendash, 1998. Preventive actions of a synthetic antioxidant in a novel animal model of AIDS dementia. Brain Res., 795: 349-357.
25. Hensley, K., K.A. Robinson, Q.N. Pye, R.A. Floyd, I. Cheng, W.A. Garland and I. Irwin, 2000. CPI-1189 Inhibits interleukin 1beta-induced p38mitogen-activated protein kinase phosphorylation: An explanation for its neuroprotective properties? Neurosci. Lett., 281: 179-182.

26. Kaiser, G.C., F. Yan and D.B. Polk, 1999. Conversion of TNF alpha from antiproliferative to proliferative ligand in mouse intestinal epithelial cells by regulating mitogen-activated protein kinase. Exp. Cell Res., 249: 349-358.

27. Rugtveit, J., E.M. Nilsen, A. Bakka, H. Carlsen, P. Brandtzaeg and H. Scott, 1997. Cytokine profiles differ in newly recruited and resident subsets of mucosal macrophages from inflammatory Bowel disease. Gastroenterology, 112: 1493-1505.

28. Kojouharoff, G., W. Hans, F. Obermeier, D.N. Mannel, T. Andus, J. Scholmerich, V. Gross and W. Falk, 1997. Neutralization of tumour necrosis factor (TNF) but not of IL-1 reduces inflammation in chronic dextran sulphate sodium-induced colitis in mice. Clin. Exp. Immunol., 107: 353-358. 